\title{
ANALISIS KEMAMPUAN KERJA PRAMUSAJI TERHADAP KELANCARAN OPERASIONAL DI FOOD AND BAVERAGE SERVICE DEPARTMENT HOTEL LOSARI BLOK $\mathrm{m} 2$ JAKARTA
}

\author{
Darmawan Damanik \\ Sekolah Tinggi Pariwisata Sahid \\ Jl. Kemiri No.22 Pondok Cabe Pamulang, Tangerang Selatan \\ Email Korespondensi: darmawan.dmnk@gmail.com
}

\begin{abstract}
ABSTRAK
Penelitian ini menggunakan metode kualitatif yang berfokus pada penguraian dan penyimpulan yang bersifat holistik dengan rangkaian data atau fakta dan generalisasi yang ada di lapangan sesuai dengan masalah penelitian. Pengumpulan data yang dilakukan melalui studi kepustakaan, observasi, wawancara, kuesioner dan dokumentasi. Teknik sampel yang digunakan dengan sampling jenuh dan purposive sampling, dan jumlah sampel sebanyak 6 (enam) orang. Metode analisis data yang digunakan penulis yaitu korelasi Pearson Product Moment, Koefisien Determinasi, uji t, hipotesis. Berdasarkan hasil dari pembahasan diperoleh bahwa nilai $\mathrm{r}$ sebesar 0,37 yang artinya bahwa kemampuan kerja pramusaji berpengaruh signifikan terhadap kelancaran operasional. Dan nilai Koefisien Determinasi sebesar 13,69 \% yang berarti pengaruh kemampuan kerja terhadap kelancaran operasional sebesar $13,69 \%$ sedangkan $86,31 \%$ berasal dari luar variabel yang diteliti seperti pendidikan dan pengalaman bekerja pada industry hospitality serta lama bekerja. Berdasarkan hasil uji t diperoleh bahwa t hitung sebesar 0,85, sedangkan t tabel dengan $\mathrm{df}=\mathrm{n}-2(6-2)=4$ dan $\alpha$ 0,025 dengan $\mathrm{t}$ tabel sebesar 2,776. Hal ini menunjukkan bahwa $\mathrm{t}$ hitung > t tabel, artinya Ho ditolak dan Ha diterima, sehingga dapat disimpulkan bahwa terdapat pengaruh yang rendah antara kemampuan kerja Pramusaji terhadap kelancaran operasional di Food and Beverage Service Department Hotel Losari Blok m2 Jakarta.
\end{abstract}

Kata Kunci : Kemampuan Kerja, Kelancaran Operasional, Pramusaji

\begin{abstract}
This research used the qualitative method which focuses on parsing and a false assertion that is holistic with a series of data or facts and generalizations that exist in the field in accordance with the research issues. Data collection is done through the study of librarianship, observation, interview, questionnaire and the documentation. Sample techniques used with sampling purposive sampling and saturated, and the number of samples as many as 6 (six) people. Methods of data analysis used the author i.e. correlation Pearson Product Moment, coefficient of Determination, $t$-test, the hypothesis. Based on the results of the discussion are obtained that the value $r$ of 0.37 which means that waiters work influential capability significantly to the smooth running of operations. And the value of the coefficient of Determination of $13.69 \%$ which means the influence of the working ability against the smooth operations of $13.69 \%$ whereas $86.31 \%$ come from outside of the variables examined, such as education and work experience in the industry hospitality and long work. Based on test results obtained that $t$ t count amounted to 0.85 , while the t table with $d f=n-2(6-2)=0.025$ and $\alpha 4$ with $t$ table of 2.776. This shows that $t$ calculate > t table, meaning that Ho is rejected and the $\mathrm{Ha}$, so that it can be concluded that there is a low influence among the working ability of the waiters against smooth operations in the Food and Beverage Service Department Hotel Losari Block m2.
\end{abstract}

Keywords: Work Ability, The Smooth Running Of Operations, Waitress 


\section{PENDAHULUAN}

Seiring dengan perkembangan industri pariwisata di Jakarta yang mengalami kemajuan pesat, maka industri pariwisata semakin mendapat perhatian khususnya dari pemerintah yakni pariwisata dapat diandalkan sebagai sumber pendapatan dan devisa negara yang utama. Perkembangan dunia perhotelan semakin pesat, sehingga mempengaruhi di kota-kota besar di Indonesia telah banyak berdiri hotel-hotel baik dikelas melati maupun di kelas berbintang, sebagai kota budaya dan pariwisata telah banyak berdiri hotel-hotel salah satunya "Losari Blok m2 Jakarta Hotel". Hotel adalah salah satu akomodasi yang menggunakan sebagian atau keseluruhan bagian banguan untuk jasa pelayanan penginapan, pelayanan makan dan minuman serta jasa lainnya bagi masyarakat yang dikelola secara komersial. Hotel Losari Blok m2 Jakarta merupakan hotel berbintang tiga bertaraf internasional, sehingga dalam menjalankan operasionalnya harus berhubungan antar departemen satu dengan departemen lainnya serta saling bekerja sama untuk mencapai tujuan bersama.

Kemampuan pramusaji yang professional dan kompeten di bidangnya sangat berperan dalam memenuhi kepuasan pengunjung hotel dan restoran khususnya. Oleh karena itu, kemampuan kerja sangatlah penting bagi sebuah perusahan. Di Restoran Hotel Losari Blok m2 Jakarta, dalam hal ini kemampuan kerja seorang pramusaji juga sangat berpengaruh terhadap kelancaran operasional di Restoran Hotel Losari Blok m2 Jakarta. Kemampuan Kerja seorang Pramusaji di Restoran Hotel Losari Blok m2 Jakarta harus mampu menghandel tamu pada saat tamu datang di depan pintu, diantar ke meja makan, memberikan menu sampai memesanan makanan sampai tamu selesai makan, dan meminta Check/bill serta meninggalkan Restoran. Seorang Pramusaji harus mampu memberikan yang terbaik guna kelancaran dalam operasional. Kemampuan kerja pramusaji di Restoran Hotel Losari Blok m2 Jakarta yaitu belum mengusai product knowledge dan standart operasional prosedur, penyebabnya karena dari tingkat pendidikan, pengalaman bekerja pada industry hospitality serta lama bekerja pada Industry Hotel. Namun hal ini sangat penting dalam meningkatkan kemampuan kerja pramusaji demi terciptanya kelancancaran dalam operasional. Oleh karena itu, Pramusajinya diwajibkan untuk mengusai Product Knowledge dan juga standar Operasional Prosedur, sehingga memudahkan karyawan dalam bekerja.

Dengan demikian perusahaan berharap agar karyawannya bekerja dengan giat, mematuhi disiplin, serta menghasilkan prestasi kerja yang baik, karena dengan cara ini perusahaan dapat memperoleh keuntungan. Pengaruh kemampuan kerja pramusaji terhadap kelancaran Operasional di Food \& Beverage Service Department Hotel Losari Blok m2 Jakarta Indonesia masih belum seperti yang diharapkan perusahaan, dan perlu ditingkatkan untuk mencapai hasil yang lebih baik lagi. Mengingat begitu pentingnya kemampuan kerja terhadap kelancaran operasional untuk menghasilkan kinerja yang optimal dalam perusahan. 


\section{Perumusan Masalah}

Dalam mengadakan penelitian, perlu dirumuskan masalah secara jelas untuk mendapatkan hasil penelitian yang baik. Berdasarkan latar belakang yang telah diuraikan diatas, maka penulis merumuskan masalah dalam penelitian ini sebagai berikut:

a. Bagaimana kemampuan kerja pramusaji terhadap kelancaran operasional di Restoran Hotel Losari Blok m2 Jakarta

b. Seberapa besar pengaruh kemampuan kerja pramusaji terhadap kelancaran operasional di Restoran Hotel Losari Blok m2 Jakarta

\section{Tujuan Penelitian}

Berdasarkan rumusan masalah diatas, tujuan penelitian ini :

a. Untuk mengetahui bagaimana kemapuan kerja pramusaji terhadap operasional di restoran

b. Untuk mengtahui seberapa besar pengaruh kemampuan kerja pramusaji terhadap kelancaran operasional di restoran Hotel Losari Blok m2 Jakarta.

\section{Pengertian Kemampuan Kerja}

Pada umumnya setiap orang mempunyai kemampuan yang berbeda-beda. Kemudian untuk mencapai hasil yang maksimal seorang karyawan harus bekerja dengan sungguh-sungguh beserta segenap kemampuan yang dimiliki ditunjang oleh sarana dan prasarana yang ada. Jika seorang pegawai bekerja dengan setengah hati maka pekerjaan yang dihasilkan tidaklah semaksimal yang diharapkan. Artinya bahwa kemampuan seseorang bisa diukur dari tingkat keterampilan dan pengetahuan yang dimiliki dalam melaksanakan tugas yang dibebankan. Menurut Ivancevich, Konopaske, Matteson (2006: 217) mendefenisikan "kemampuan adalah bakat seseorang untuk melakukan tugas fisik ataupun mental'Menurut

Adapun pendapat menurut Wibowo (2007: 86) mengemukakan bahwa :

"Kemampuan diartikan sebagai untuk melaksanakan ataupun melakukan suatu pekerjaan atau tugas yang dilandasi oleh keterampilan dan pengetahuan kerja yang dituntut oleh pekerjaan tersebut”.

Menurut Robbins (2015: 52), kemampuan individu pada hakekatnya tersusun dari dua faktor yaitu mengenai kemampuan intelektual dan kemampuan fisik.

Tabel 2.1 Dimensi dan indikator kemampuan Intelektual

\begin{tabular}{|l|l|l|}
\hline Dimensi & Deskripsi & Contoh Pekerjaan \\
\hline Kecerdasan angka & $\begin{array}{l}\text { Kemampuan untuk melakukan } \\
\text { aritmatika yang cepat dan } \\
\text { akurat }\end{array}$ & $\begin{array}{l}\text { Akuntan: menghitung pajak } \\
\text { penjualan atas serangkaian } \\
\text { item }\end{array}$ \\
\hline Komprehensi verbal & $\begin{array}{l}\text { Kemampuan memahami apa } \\
\text { yang dibaca atau didengar dan } \\
\text { hubungan antarkata }\end{array}$ & $\begin{array}{l}\text { Manajer pabrik: mengikuti } \\
\text { kebijakan perusahan dalam } \\
\text { perekrutan }\end{array}$ \\
\hline Kecepatan Perseptual & $\begin{array}{l}\text { Kemampuan untuk } \\
\text { mengidentifikasi kesamaan } \\
\text { dan perbedaan visual secara } \\
\text { cepat dan akurat }\end{array}$ & $\begin{array}{l}\text { Invesgator kebakaran: } \\
\text { mengidetifikasi petunjuk } \\
\text { untuk memastikan biaya } \\
\text { kerugian kebakaran }\end{array}$ \\
\hline
\end{tabular}




\begin{tabular}{|l|l|l|}
\hline Nalaran induktif & $\begin{array}{l}\text { Kemampuan untuk } \\
\text { mengidetifikasi urutan logis } \\
\text { dalam sebuah masalah dan } \\
\text { kemudian memecahkan } \\
\text { masalah }\end{array}$ & $\begin{array}{l}\text { Peneliti pasar: meramalkan } \\
\text { permintaan untuk sebuah } \\
\text { produk dalam periode } \\
\text { waktu mendatang }\end{array}$ \\
\hline Nalaran deduktif & $\begin{array}{l}\text { Kemampuan mengunakan } \\
\text { logika dan menilai implikasi } \\
\text { sebuah argument }\end{array}$ & $\begin{array}{l}\text { Pengawas: memilih antara } \\
\text { dua saran yang berbeda } \\
\text { yang ditawarkan pekerja }\end{array}$ \\
\hline Analisasi spasial & $\begin{array}{l}\text { Kemampuan untuk } \\
\text { mengimajinasikan bagaiman } \\
\text { sebuah objeck terlihat jika } \\
\text { posisinya dalam ruang diubah }\end{array}$ & $\begin{array}{l}\text { Dekator interior: mendekor } \\
\text { ulang sebuah kantor }\end{array}$ \\
\hline Jabatan & $\begin{array}{l}\text { Kemampuan untuk } \\
\text { mempertahankan dan } \\
\text { meningkatkan pengalaman } \\
\text { masa lalu }\end{array}$ & $\begin{array}{l}\text { Agen penjualan: mengingat } \\
\text { nama-nama pelanggang }\end{array}$ \\
\hline
\end{tabular}

Sumber: Robbins (2015)

Tabel 2.2 Dimensi dan indikator kemampuan fisik

\begin{tabular}{|c|c|}
\hline Faktor kekuatan & \\
\hline 1. Kekuatan Dinamis & $\begin{array}{l}\text { Kemampuan untuk menggunakan dorongan } \\
\text { otot berulang-ulang atau terus-menerus } \\
\text { sepanjang waktu }\end{array}$ \\
\hline 2. Kekuatan Otot & $\begin{array}{l}\text { Kemampuan untuk menggunakan kekuatan } \\
\text { otot dengan menggunakan otot tubuh } \\
\text { (khususnya bagian abdominal) }\end{array}$ \\
\hline 3. Kekuatan statis & $\begin{array}{l}\text { Kemampuan untuk menggunakan kekuatan } \\
\text { atas objek eksternal }\end{array}$ \\
\hline 4. Kekuatan Eksplosif & $\begin{array}{l}\text { Kemampuan untuk menghabiskan } \\
\text { maksimum energy dalam satu atau } \\
\text { serangkaian tindakan eksplosif }\end{array}$ \\
\hline Faktor Fleksibilitas & \\
\hline 5. Fleksibilitas Memanjang & $\begin{array}{l}\text { Kemampuan untuk menggerakan otot tubuh } \\
\text { dan punggung sejauh mungkin }\end{array}$ \\
\hline 6. Fleksibilitas Dinamis & $\begin{array}{l}\text { Kemampuan untuk membuat pergerakan } \\
\text { fleksibel cepat dan berulang }\end{array}$ \\
\hline Faktor Lainnya & \\
\hline 7. Koordinasi Tubuh & $\begin{array}{l}\text { Kemampuan untuk mengoordinasikan } \\
\text { tindakan simultan dari bagian tubuh berbeda }\end{array}$ \\
\hline 8. Keseimbangan & $\begin{array}{l}\text { Kemampuan untuk mempertahankan } \\
\text { keseimbangan meskipun ada dorongan yang } \\
\text { mengganggu keseimbangan }\end{array}$ \\
\hline 9. Stamina & $\begin{array}{l}\text { Kemampuan untuk melanjutkan usaha } \\
\text { maksimum yang membutuhkan usaha } \\
\text { panjang }\end{array}$ \\
\hline
\end{tabular}

Sumber: Robbins (2015) 


\section{Pengertian Kelancaran Operasional}

Demi tercipta kelancaran dalam suatu Operasional dibutuhkan suatu panduan dalam menjalankan pekerjaan tertentu. Panduan Operasional atau yang biasanya dikenal dengan Standard Operational Procedure (SOP).

Menurut Indah Puji, 2014:30 dinyatakan bahwa tujuan dari SOP sebagai berikut:

a. Sebagai acuan dalam pelaksanakan kegiatan tertentu bagi sesama perkerja dan supervisor

b. Untuk menjaga konsistensi tingkat penampilan kinerja atau kondisi tertentu dan kemana petugas dan lingkungan dalam melaksanakan sesuatu tugas dan pekerjaan tertentu.

c. Untuk menghindari kegagalan dan kesalahan (dengan demikian menghindari dan mengurangi konflik), keraguan, duplikasi serta pemborosan dalam proses pelaksanaan kegiatan.

d. Untuk lebih menjamin penggunaan tenaga dan sumber daya secara efisien dan efektif.

Sedangkan fungsi Standar Operasional Prosedur (SOP) menurut Indah Puji, ( 2014: 35 diantaranya :

a. Memperlancar tugas petugas/ pegawai atau tim/unit kerja

b. Sebagai dasar hokum bila terjadi penyimpangan

c. Mengarahkan petugas/pegawai untuk sama-sama disiplin dalam bekerja

d. Sebagai pedoman dalam melaksanakan pekerjaan rutin.

Fungsi operasional manajemen menurut Prof. Dr. Tjutju Yuniarsih \& Dr. Suwatno, M.Si. ( 2006 : 6-7) meliputi:

a. Perencanaan Tenaga Kerja

Perencanaan tenaga kerja merupakan operasi dari manajemen sumber daya manusia.

b. Pengembangan Tenaga kerja

Penegmbangan tenaga kerja merupakan suatu kondisi yang menunjukkan adanya peningkatan-peningkatan kualitas tenaga kerja sehingga dapat mengurangi ketergantungan organisasi untuk menarik karyawan baru.

c. Penilaian Prestasi Kerja

Penilaian prestasi kerja merupakan salah satu aspek yang penting dalam pengelolahan sumber daya manusia. Dengan adanya penilaian prestasi kerja.

d. Pemberian Kompensasi

Fungsi pemberian kompensasi meliputi kegiatan pemberian balas jasa kepada para karyawan.

e. Pemeliharaan Tenaga Kerja

Didalam pemeliharaan tenaga kerja ada pelaksanaan apek ekonomis dan non ekonomis yang diharapkan dapat memberikan ketenangan kerja dan konsentrasi penuh bagi pekerja guna menghasilkan prestasi kerja yang diharapkan oleh organisasi.

f. Pemberhentian

Pemberhentian adalah fungsi operatif terakhir manajemen sumber daya manusia. Fungsi pemberhentian harus mendapat perhatian yang serius dari manajer SDM 
karena telah diatur oleh undang-undang dan mengikat bagi perusahan maupun karyawan.

\section{METODOLOGI PENELITIAN}

Rancangan metode penelitian yang digunakan pada penelitian ini adalah metode kualitatif yaitu melaksanakan penelitian dengan cara yang deskriptif, sistematis, terkontrol dan empiris. Penelitian kualitatif ini lebih menekankan kepada cara berpikir yang lebih positif yang bertitik tolak dari fakta sosial yang ditarik dari realitas objektif. Penelitian kualitatif adalah penelitian yang bersifat ilmiah, oleh karena itu semua peneliti harus berbekal teori.

Metode yang digunakan pada penelitian ini adalah kualitatif. Pengertian kualitatif statistik deskriptif menurut Kusmayadi (2004 : 6) dinyatakan bahwa :

"Ilmu statistik yang mempelajari cara mengumpulkan data, menggolongkan data, menyimpulkan dan menyajikannya dalam bentuk yang lebih ringkas dan jelas ke dalam tabel, grafik-grafik, dan gambar-gambar"

Jangan diartikan dalam penelitian kualitatif, peneliti tidak mengumpulkan dan menggunakan angka-angka dalam analisis data dan penulisan laporan penelitian. Metode Penelitian Kualitatif perlu mengumpulkan dan menganalisis angka-angka apabila diperlukan.

\section{Prosedur Penarikan Sampel}

Dalam proses penelitian, populasi berarti sekelompok subjek atau objek menjadi sasaran penelitian untuk dipelajari dan diambil kesimpulan. Sedangkan sampel adalah prosedur pengambilan data dimana hanya sebagian populasi saja yang diambil dalam penelitian. Populasi dalam penelitian ini adalah seluruh karyawan di Food and Beverage Service DepartmentHotel Losari Blok m2 Jakarat yang berjumlah 6 orang karyawan sesuai data hasil observasi. Sedangkan untuk menentukan sampel penelitian ini, peneliti menggunakan teknik dengan teknik sampling jenuh. Menurut Prof. DR. Sugiyono (2015:124) "sampling jenuh adalah teknik penentuan sampel bila semua anggota populasi digunakan sebagai sampel”. Disamping itu peneliti juga menggunakan teknik purposive sampling. Menurut Sugiyono (2015:124) "purpose sampling adalah teknik penentuan sampel dengan pertimbangan tertentu".

Berdasarkan teknik-teknik yang telah disebutkan sebelumnya, peneliti berusaha mengumpulkan data-data dari informan yang dianggap mengerti tentang masalah yang diteliti serta pemilihan informan dapat berkembang sesuai dengan kebutuhan peneliti.

\section{Prosedur Pengumpulan Data}

Teknik pengumpulan data adalah hal yang paling utama dalam sebuah penelitian, karena tujuan dari sebuah penelitian adalah mendapatkan data yang dapat dipercaya. Tanpa mengetahui teknik pengumpulan data, maka peneliti tidak akan mendapatkan data yang memenuhi standar yang ditetapkan.

Data yang digunakan peneliti dalam penelitian ini dikumpulkan melalui :

\section{a. Data Primer}

Data primer yaitu data yang dikumpulkan sendiri oleh peneliti langsung dari sumber pertama atau tempat objek penelitian, melalui kuesioner,observasi dan wawancara. 
Contohnya peneliti memberikan pernyataan dalam bentuk Hardcopy kepada informan untuk diisi sesuai kondisi dan situasi yang ada dilapangan.

\section{b. Data Sekunder}

Data sekunder yaitu data penunjang untuk melengkapi data penelitian. Data penelitian ini diperoleh dari buku-buku, website dan literature lainnya yang berhubungan dengan penelitian.

\section{Metode Analisis Data}

Analisis data adalah suatu upaya atau cara untuk mengelolah data menjadi informasi sehingga karakteristik data tersebut bisa dipahami dan bermanfaat untuk solusi permasalahan, terutama masalah yang berkaitan dengan penelitian. Dalam menganalisis data dalam penelitian ini peneliti menggunakan analisis data kualitatif, dimana data diperoleh baik melalui wawancara, kuisioner, dokumentasi untuk mengetahui kemampuan kerja staf terhadap kelancaran operasional di food and beverage service Department Hotel Losari Blok m2 Jakarta.

Berdasarkan data yang dikumpulkan, maka langkah selanjutnya adalah membuat metode analisis data. Pada penelitian ini metode yang digunakan peneliti sebagai yaitu :

a. Koefisien Korelasi Pearson Product Moment

$$
r_{x y}=\frac{n \sum x y-\left(\sum x\right)\left(\sum y\right)}{\sqrt{\left(n \sum x^{2}\right.}-\left(\sum x\right)^{2}\left(n \sum y^{2}-\left(\sum y\right)^{2}\right)}
$$

Keterangan :

$\mathrm{r} \quad$ : Korelasi pearson product Moment

$\mathrm{n}$ : Jumlah sampel (responden)

x : Kemampuan Kerja Pramusaji (Variabel bebas)

y : Kelancaran Operasional (Variabel terikat)

Berdasarkan hasil penelitian maka akan dihasilkan suatu perhitungan korelasi antara kemampuan kerja staf dan kelancaran operasional. Besar Korelasi PPM dengan lambang $\mathbf{- 1} \leq \mathbf{r} \leq+\mathbf{1}$

Keterangan:

$\mathrm{r}=-1 \longrightarrow$ Korelasi negative sempurna (hubungan $\mathrm{x}$ dan $\mathrm{y}$ tidak searah)

$\mathrm{r}=0 \longrightarrow$ Tidak ada korelasi

$\mathrm{r}=+1 \quad \longrightarrow$ Korelasi sangat kuat (hubungan $\mathrm{x}$ dan y searah) 
Interval Nilai Koefisien Dan kekuatan Hubungan sebagai berikut:

Tabel 3.1 Inteprestasi Nilai Koefisien Korelasi

\begin{tabular}{|c|l|}
\hline Interval Koefisien & \multicolumn{1}{|c|}{ Tingkat Hubungan } \\
\hline $0,80-1,000$ & Sangat Kuat \\
$0,60-0,799$ & Kuat \\
$0,40-0,599$ & Cukup Kuat \\
$0,20-0,399$ & Rendah \\
$0,00-0,199$ & Sangat Rendah \\
\hline & \\
\hline
\end{tabular}

b. Koefisien Determinasi

$$
\mathrm{Kd}=\mathbf{r}^{2} \times 100 \%
$$

Keterangan :

Kd : Koefisien Determinasi

r : Koefisien Korelasi

c. Uji Hipotesis

$$
t=\frac{r \sqrt{n-2}}{\sqrt{1-r^{2}}}
$$

Ketentuan kriteria penerimaan Ho ditentukan oleh derajat signifikan yang secara konvensional terbagi menjadi 3, yaitu:

$\alpha=0,10$ dimana Ho diterima jika $\mathrm{t} \leq 0,10 ; \mathrm{n}-2 \mathrm{~s} \alpha$

$=0,05$ dimana Ho diterima jika $\mathrm{t} \leq 0,05 ; \mathrm{n}-2 \alpha=0,01$

dimana Ho jika $\mathrm{t} \leq 0,01 ; \mathrm{n}-2$

Untuk menguji dua sisi lebih banyak digunakan kriteria penerimaan Ho dengan derajat $\alpha=0,05$

Perumusan hipotesis menggunakan $\rho$ (rho) yaitu nilai koefisien korelasi yang sebenarnya.

Ho $: \rho=0$ artinya tidak ada korelasi antara variabel $\mathrm{X}$ dan $\mathrm{Y}$ (hubungan tidak signifikan)

Ho $: \rho \neq 0 \quad$ artinya ada korelasi antara $\mathrm{X}$ dan $\mathrm{Y}$ (tidak sama dengan nol, mungkin lebih besar atau lebih kecil dari nol, hubungan signifikan). 


\section{HASIL DAN PEMBAHASAN}

Berdasarkan hasil penelitian yang dilakukan oleh peneliti dengan menggunakan rumus Koefisien Korelasi Product moment

Dengan menggunakan rumus di bawah ini, untuk menghitung tingkat hubungan antara kemampuan kerja pramusaji terhadap kelancaran operasional di Hotel Losari Blok m2 Jakarta.

Dengan keterangan jumlah berdasarkan data renponden kuesioner:

$\sum X=284 \quad \sum X Y=12.882$

$\sum \mathrm{Y}=272 \quad \sum \mathrm{X}^{2}=13.450 \quad \sum \mathrm{Y}^{2}=12.384$

Maka perhitungan adalah sebagai berikut:

$$
\begin{aligned}
& r_{x y}=\frac{n \sum x y-\left(\sum x\right)\left(\sum y\right)}{\sqrt{\left(n \sum x^{2}-\left(\sum x\right)^{2}\left(n \sum y^{2}-\left(\sum y\right)^{2}\right)\right.}} \\
= & \frac{6(12.882)-(284)(272)}{6(13.450)-(284)^{2}\left(6(12.384)-(272)^{2}\right.} \\
= & \frac{77.292-77.248}{\sqrt{(80.700-80.656)(74.304-73.984)}} \\
= & \frac{44}{\sqrt{(44)(320)}} \\
= & \frac{44}{\sqrt{14.080}} \\
= & \frac{44}{118.659} \\
= & 0,37
\end{aligned}
$$

Pengaruh kemampuan kerja pramusaji terbukti dengan hasil penelitian nilai $\mathrm{r}$ sebesar 0,37 berarti Koefisien Korelasi menunjukkan hubungan positif signifikan antara kedua variabel namun pengaruhnya rendah. Dapat dilihat pada tabel Inteprestasi Nilai Koefisien Korelasi.

Seberapa besar pengaruh kemampuan kerja pramusaji terhadap kelancaran operasional di Restoran Hotel Losari Blok m2 Jakarta dapat dihitung menggunakan Koefisien Determinasi

$$
\begin{aligned}
\mathbf{K d} & =\mathbf{r}^{2} \times \mathbf{1 0 0} \% \\
& =(0,37)^{2} \times 100 \% \\
& =0,1369 \times 100 \% \\
& =13,69 \%
\end{aligned}
$$

Dari hasil perhitungan koefisien determinasi sebesar 13,69\% dan dapat ditarik kesimpulan bahwa pengaruh kemampuan kerja pramusaji terhadap kelancaran operasional di food and beverage service Depatment Hotel Losari Blok m2 Jakarta sebesar 13,69\% artinya pengaruh kemampuan kerja terhadap kelancaran operasional 
positif signifikan namun pengaruhnya Rendah dan sebesar $86,31 \%$ berasal dari variabel luar yaitu faktor lain seperti, pendidikan dan pengalaman bekerja pada industry hospitality serta lama bekerja di Hotel Losari Blok m2 Jakarta.

\section{Uji t}

Dari hasil perhitungan koefisien korelasi tersebut, maka perlu dilakukan perhitungan signifikan untuk mengetahui apakah adanya pengaruh antara kedua variabel tersebut berlaku untuk seluruh populasi atau hanya berlaku untukresponden yang merupakan sampel yang berjumlah 6orang serta untuk mengetahui hipotesis mana yang diterima, dengan menggunakan rumus sebagai berikut:

$$
\begin{aligned}
t & =\frac{\mathrm{r} \sqrt{n-2}}{\sqrt{1}-r^{2}} \\
& =\frac{0,37 \sqrt{6-2}}{\sqrt{1}-0,37^{2}} \\
= & \frac{0,37(2)}{1-0,1369} \\
= & \frac{0,74}{0,8631}
\end{aligned}
$$

thitung $=0,85$

Maka dapat diketahui bahwa t hitung sebesar 0.85 selanjutnya dengan: $\mathrm{df}=\mathrm{n}-2=6-2=4$ dan

$\alpha=5 \%(0,05 / 2=0,025)$ maka didapat bahwa nilai $\mathrm{t}$ tabel $=2,776$

Dengan menguji dua sisi, hasil t tabel diperoleh sebesar 2,776 jika dilihat dari

kriteria yang digunakan:

1. Jika thitung $>\mathrm{t}$ tabel, maka Ho ditolak dan Ha diterima

2. Jika t hitung $<\mathrm{t}$ tabel, maka Ho diterima dan Ha ditolak

Dari hasil perhitungan Uji t di atas bahwa thitung lebih kecil dari pada t tabel 0,85 $<$ 2,776 dan dapat diartikan bahwa hipotesis tidak mempunyai pengaruh antara variabel ditolak (Ho diterima) dan hipotesis yang mempunyai pengaruh antara variabel diterima (Ha ditolak).

Sehingga disimpulkan bahwa Kemampuan Kerja Pramusaji Terhadap Kelancaran OperasionalDi Food And Beverage Service Department Hotel Losari Blok m2 Jakarta ada pengaruh.

\section{KESIMPULAN DAN SARAN}

1. Kesimpulan

Berdasarkan uraian dan analisis yang telah dikemukan sebelumnya, maka penulis menyimpulkan :

a. Pengaruh kemampuan kerja pramusaji menunjukkan hubungan yang Rendah, terbukti dengan hasil penelitian nilai $r$ sebesar 0,37 berarti Koefisien Korelasi menunjukkan hubungan positif signifikan antara kedua variabel namun bersifat rendah 
b. Pengaruh kemampuan kerja pramusaji terhadap kelancaran operasionaal nilai kd sebesar $13,69 \%$ dan $86,31 \%$ berasal dari luar variabel, berdasarkan penelitian yang penulis teliti seperti, tingkat pendidikan, pengalaman bekerja pada industry hospitality dan lama bekerja.

c. Perhitungan uji t menghasilkan thitung sebesar 0,85 , sedangkan jika dibandingkan dengan t tabel dengan $\mathrm{df}=\mathrm{n}-2(6-2)=4$ dan $(\alpha) 0,025$ diperoleh $\mathrm{t}$ tabel sebesar 2,776. Hal ini menunjukan bahwa $t$ hitung < t tabel, artinya Ho ditolak dan $\mathrm{Ha}$ diterima, sehingga di simpulkan bahwa ada pengaruh yang signifikan antara kemampuan kerja pramusaji terhadap kelancaran operasional di Food and Beverage Service Depatment Hotel Losari Blok m2 Jakarta.

d. Dari hasil pengujian diatas dapat dibuktikan bahwa uji hipotesa telah dapat ditentukan hasilnya yaitu Ho (tidak terdapat pengaruh antara kemampuan kerja pramusaji terhadap kelancaran di operasional ) ditolak, dan Ha (terdapat pengaruh antara kemampuan kerja pramusaji terhadap kelancaran operasional) diterima.

e. Bahwa faktor yang berhubungan dengan kemampuan kerja terhadap kelancaran operasional berupa memberikan arahan dan dorongan berupa pemberian kompensasi, komunikasi yang baik antar rekan kerja, mendapat jaminan kesehatan dan keselamatan, mendapatkan penghargaan serta motivasi dalam bekerja kepada setiap pramusaji yang bertujuan agar setiap pramusaji bekerja sesuai dengan standar SOP yang sudah ditentukan perusahaan. Kinerja karyawan akan meningkatkan antara lain karyawan memiliki rasa tanggung jawab terhadap tugas yang diberikan dan bekerja dengan maksimal sehingga mendukung operasional di Food and Beverage Service Department Hotel Losari Blok m2 Jakarta.

2. Saran

Berdasarkan hasil penelitian dan kesimpulan, maka penulis ingin menyampaikan beberapa saran, antar lain :

a. Sebaiknya Food and Beverage Service Department lebih ditingkatkan kembali kemampuan kerja kepada pramusaji sehingga kinerja pramusaji meningkat serta hubungan kerjasama agar pekerjaan dapat berjalan dengan lancar dan membantu operasional Hotel Losari Blok m2 Jakarta.

$b$. Lebih baik adanya program training bagi karyawan mengenai product knowledge secara periodik agar lebih meningkatkan lagi kinerja di bidang masing-masing Department

c. Sebaiknya karyawan harus memiliki inisiatif yang tinggi untuk mengerjakan pekerjaan dan telah mengetahui pekerjaanya serta mampu membuat kinerja lebih baik lagi. 


\section{DAFTAR PUSTAKA}

Gibson, J. L. (2001). Organisasi dan Manajemen: Perilaku, Struktur, Proses. Erlangga.

Hartatik, I. P. (2014). Buku Praktis Mengembangkan SDM. Yogyakarta: Laksana.

Hasibuan, M. S., \& Hasibuan, H. M. S. (2016). Manajemen sumber daya manusia. Bumi Aksara.

Ivancevich, J. M., Konopaske, R., \& Matteson, M. T. (2006). Perilaku dan manajemen organisasi (Jilid 1 Edisi Ketujuh). Terjemahan Gina Gania). Jakarta: Erlangga.

Kusmayadi. (2004). Statistika Pariwisata Deskriptif. Jakarta: Gramedia Pustaka

Larasati, S. (2016). Excellent Hotel Operation. Yogyakarta: Ekuilibria.

Robbins, S. P., Judge, T. A., Angelica, D., \& Resthi, W. (2016). Perilaku Organisasi I: Organizational Behavior. (2009). Perilaku organisasi. Jakarta: Salemba

Sihite, R. (2000). Food Service (tata hidang). Surabaya. Penerbit SIC.

Sugiyono. (2015). Metode Penelitian Pendidikan Kuantitatif, Kualitatif ,R\&D. Bandung: affabeta

Tjutju, Y \& Suwatno. (2016). Manajemen Sumber Daya Manusia. Bandung: Alfabeta Wibowo. (2007). Manajemen Kinerja, Jakarta: Raja Grafindo Persada 